\title{
Study on Translation Strategies of News Headlines from the Perspective of Chesterman's Translation Ethics
}

\author{
Peiying Guo, Jiahui Chen \\ School of Arts and Sciences, Shaanxi University of Science and Technology (SUST), Xi'an, China \\ Email: 290917128@qq.com
}

How to cite this paper: Guo, P. Y., \& Chen, J. H. (2021). Study on Translation Strategies of News Headlines from the Perspective of Chesterman's Translation Ethics. Open Journal of Modern Linguistics, 11, 520-528. https://doi.org/10.4236/ojml.2021.114039

Received: June 16, 2021

Accepted: July 12, 2021

Published: July 15, 2021

Copyright $\odot 2021$ by author(s) and Scientific Research Publishing Inc. This work is licensed under the Creative Commons Attribution International License (CC BY-NC 4.0).

http://creativecommons.org/licenses/by-nc/4.0/ (c) (i) Open Access

\begin{abstract}
As the quickest access for readers to get the key of the content, news headline translation has aroused more and more researchers' attention. Different from other studies on this subject, this paper studies the English to Chinese translation strategies of news headlines by analyzing 137 English to Chinese headlines concerning coronavirus pandemic from "Language Tips" in China Daily Website. The two translation strategies (imitation and variation) primarily adopted in the selected news headlines are clarified, and specific translation methods under these two strategies are further discussed based on Chesterman's Translation Ethics.
\end{abstract}

\section{Keywords}

News Headlines, Chesterman's Translation Ethics, Translation Strategies

\section{Introduction}

Online news has become one of the main sources for readers to obtain information and follow up on current events. According to the data from the China Industry Information website, by December 2020, the number of online news users in China is 742.74 million, accounting for $75.1 \%$ of the total netizens and increased by 12.02 million compared with March 2020. As a portion of news, headlines are an important part for helping readers instantly capture the main idea of the news they are interested in. In terms of medium disseminating news, news headline is one of the keys for medium to take a leading role in news communication (Chen Yi-qiang, 2020). Thus, providing high-quality E-C news headline translation online is particularly significant for Chinese readers to learn about 
international news.

In recent years, the studies on the news headline translation in China tend to be microscopic and modelized. Literature shows that most studies on news headline translation focus on translation methods or translation techniques for news headline translation, and on translation features of news headline translations. Different from the above studies, this paper adopts Chesterman's translation ethics, which provides a macro perspective and expounds translation strategies based on specific translator's subjectivity.

In this paper, bilingual news headlines relevant to coronavirus pandemic from January $29^{\text {th }}$ to July $7^{\text {th }}$ in 2020 are selected from the "Language Tips" of China Daily. The E-C translation of 137 headlines is analyzed based on Chesterman's translation ethics model, aiming to explore the translation strategies of news headlines. This paper is expected to raise further attention on purposes and functions of the translation productions, but not only on the models of translation. The bilingual E-C news on the China Daily Website may be taken as references by many English learners and translators to follow up international news, hence the study on their headline translations can offer a new perspective to better study on the E-C bilingual news.

\section{Chesterman's Translation Ethics Model and Relevant Studies on Translation}

The consideration of translation ethics was initially originating from the refection on balancing the source text and the target text, which is a kind of ethics. Whether a translation strategy is adopted depends on the selection by the translator, who involves various sociocultural practices and processes. Hereafter, the studies on translation have been conducted more in the cultural aspects and broad areas of human culture, such as the combination with politics, ideology, anthropology, history, etc. After the 1970s and 1980s, ethical issues concerning translation have been gaining more attention and Chesterman is one of the researchers who have deep and comprehensive studies on ethics of translation (Peng Ping, 2013).

Chesterman divides translation ethics mainly into four models based on the existing translation ethics in the west, namely, ethics of representation, ethics of service, ethics of communication, norm-based ethics, and proposed ethics of professional commitment borrowing the oath for the medical profession. This paper mainly analyzes the translation strategies of news headlines from ethics of service, ethics of communication, and norm-based ethics. Ethics of service emphasizes the function of translation-the translation should satisfy the client and can be accepted by the readers; ethics of communication highlights cultural communication between the language of the source text and target text ( Hou $\mathrm{Li}$ \& Xu Lu-zhi, 2013); norm-based ethics believe that the norms of translation production should be the ones required by current mainstream standards of the target language. 


\section{Translation Strategies and Translator's Subjectivity}

The translator is the subject during translation and has a decisive influence on translation activities. As the center of translation activities, translators are "at the interaction points of various influences between different languages and cultures. Translators are not only the subject during translation but also the cornerstone of the translation activities." (Ge Xiao-qin, 2002).

The translator's subjectivity is affected by translation ethics, and reflected by the translation strategies. The function of the source and target text, the goal of the translation and the readers of the target language are all factors considered while translators' subjectivity plays its role. As the translator is a "free subject" to take on the ethical responsibility of translation (Wang Xiu-lu, 2016), specific translation methods are selected guided by translation ethics.

Imitation and variation translation are the most adopted strategies in the E-C translations of news headlines selected in this paper. Imitation is to change the meaning and syntactic structure of the source text in translation, so that the content and main idea of the target text are similar to those of the source text; compared with imitation, the content and main idea of the target text using variation translation are different from those of the source text (Xiong Bing, 2014). The highest level of rein is given to translators while adopting imitation and variation translation.

\section{Translation Strategies of News Headlines E-C Translation from the Perspective of Translation Ethics}

"China Daily" is an authoritative website and one of the six national major media websites in China, and has been a national English newspaper since its inception in 1981. The "Language Tips" column of the China Daily Website offers daily bilingual E-C news for readers. The translation strategies adopted in the headline's translation of "Language Tips" are worth using for reference. The E-C bilingual news headlines were selected according to the same background and the time span was almost half a year.

Among the selected 137 bilingual headlines of news reporting COVID-19 pandemic and related events in "English Tips" on the China Daily Website. The applied translation strategies in the selected bilingual news headlines are shown in Table 1.

From Table 1, it can be seen that imitation and variation translation account for over $70 \%$. The E-C translation strategies of news headlines in the "English Tips" are highly flexible, and the imitation and variation translation are the main

Table 1. Applied translation methods.

\begin{tabular}{cccc}
\hline & Other translation strategies & Imitation & Variation translation \\
\hline Number & 38 & 63 & 36 \\
Proportion & $27.73 \%$ & $45.99 \%$ & $26.28 \%$ \\
\hline
\end{tabular}


translation strategies adopted in the E-C translation of news headlines in the "English Tips".

Imitation and variation translation can be subdivided according to the specific translation practices. Totally 10 translation methods are included in imitation and variation translation, as shown in Table 2.

\subsection{Translation Strategies Based on Ethics of Service}

Ethics of service requires translators to target the needs of clients and translation users. In other words, the translators need to adjust the translation methods according to the aims of the translation products and the actual environment.

Ethics of service plays its role in the translation of China Daily's bilingual news headlines by providing readers with referable Chinese and assisting readers in English reading. Since the readers of China Daily's bilingual news are mainly advanced English learners who have mastered basic knowledge in reading English, comprehensive translations are not a must for those readers. They can recognize the content based on the texts of the news. Therefore, the function of the headline E-C translation is helping readers quickly filter news information and arouse readers' interest. In addition to translating the information contained in the source text headlines, the translated headlines also refine the main information of the news for readers, or adding interesting information to attract readers.

\section{1) Adding particulars}

Adding particulars includes adding detail, example, cause, and effect, etc. When translating news headlines, the translator adds further information that is generally directly related to the reported events, so that readers can have a basic understanding of the news.

Example 1

ST: Coronavirus: The unusual ways countries are managing lockdowns

TT: 按身份证尾号出行、男女分开出门……盘点一些奇特的居家令

The translator provides a supplementary explanation of the "unusual ways" so that readers can see from the headline how "unusual" the ways are, forming a further understanding of the "unusual ways".

Table 2. Methods of imitation and variation translation.

Shifting perspective
Adding particulars
Methods of imitation
Adding interactive semantic content
Adding comment
Omitting background information
Rethods of variation
translation
Replacing unfamiliar information
Placing the key information at the beginning
Replacing micro information
Replacing plain narration




\section{2) Adding comments}

Adding relevant comments can be a review on the news, or a general comment on the significance of the event, highlighting the influences of the news event and inspiring readers to think about the news event.

Example 2

ST: Italians are singing on their balconies to create community in the age of coronavirus

$\mathrm{TT}$ : 疫情夺不走欢乐: 意大利人在阳台上齐声歌唱相互鼓劲

The translator makes a general comment on this report: the epidemic does not get rid of joy. It is an expression of appreciating the optimism for life.

\section{3) Omitting background information}

Omitting the translation of background information can provide space for the title to supplement other information, because readers who concern news are often sensitive to the news background, especially the major and long-lasting event.

\section{Example 3}

ST: Astronauts land back on Earth transformed by pandemic

TT: 国际空间站三名宇航员返航后发现地球变了

The translator omits the translation of "by pandemic" and adds relevant information describing the returning astronauts. The news was reported in April, during which discussions about the COVID-19 pandemic have been prevailing. Consequently, readers can associate news with the major background without mentioning it.

\section{4) Placing the key information at the beginning}

Comparatively, English language is subject prominent while Chinese language is topic prominent. Therefore, the key information should be placed at the beginning of a sentence in English to Chinese Translation.

Example 4

ST: Thais queue for booze before 10-day alcohol ban in Bangkok

TT: 泰国新年临近曼谷实施 10 天禁酒令

The source text tells that Thais line up to buy alcohol before the 10-day alcohol ban in Bangkok, while based on the content of the news, the translator places at the beginning and emphasizes that Bangkok implemented alcohol ban because of the need of curbing epidemic during the new year of Thais. Compared with the source text, the target text highlights the topic.

\section{5) Replacing micro information}

Replacing micro information is a translation method with obvious changes in the source text. The translated news headline summarizes and refines the micro-information of the original headline to present a headline giving macro information, so that readers can read the bilingual news headlines at both micro and macro levels.

Example 5

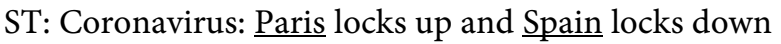




\section{TT: 遏制新冠肺炎蔓延多国进入紧急状态}

The source text means that Paris and Spain enter the lockdown stage. But the target text reveals, based on the content of the source news, that “多国(countries)" enter the lockdown stage for the prevention and control of the COVID-19 pandemic.

\subsection{Translation Strategies Based on Ethics of Communication}

Ethics of communication requires the translator to "balance" between the original language and the target language, and to ensure smooth communication between the source and target text. Most of the bilingual news provided by China Daily are initially released by the foreign English media. News as such contain a large amount of foreign cultural information and are expressed in different patterns. Therefore, some E-C translations of news headlines provided by China Daily try to shorter the cultural distance between the target language and the original language, and to enable the readers to perceive the information while to convey the basic information of the original headlines.

\section{1) Shifting perspective}

Shifting perspective for imitation allows the target text to comply with the logic pattern in Chinese, making readers understand the main information more quickly.

Example 6

ST: France has banned online sales of nicotine substitutes after a study showed smokers are less likely to be admitted for COVID-19

TT: 吸烟不容易得新冠肺炎? 这项研究引发了法国的尼古丁禁令

If translated by literal translation, the target text may be as follows:

“在一份研究显示吸烟者更不易患上新冠肺炎后, 法国禁止了尼古丁烟草 的线上销售。”

The target text as such is very lengthy and in a perspective of a statement, which is not conducive to the readers' direct understanding of information. In contrast, the translation in Example 6 informs the results of “研究(the study)” directly by an individual question, followed by the impact of the study on nicotine sales. The headline covers the news from a causal perspective, making the information clear at a glance.

\section{2) Replacing unfamiliar information}

Some information in the source text is relatively unfamiliar to readers due to cultural or cognitive differences. Replacing the unfamiliar information with the one that familiar to the readers of target language to make the information easier to understand.

Example 7

ST: Mask in a restaurant? This one can gobble like Pac-Man

TT: 新发明: 口罩装上 “机械嘴” 吃饭时不用摘

The news introduces a newly invented mask for the COVID-19 epidemic, and

"Pac-Man" is an animated character in a game. Keeping moving and swallowing beans is one of the characteristics of the Pac-Man. People can eat without re- 
moving the mask if they wear this newly invented mask and Pac-Man is a figurative image for users of the new mask. Thus, the news headline compares this action to Pac-Man gobbling. However, most Chinese readers are not familiar with “Pac-Man”, so the “机械嘴(mechanical mouth)” is adopted in the target text, which is a familiar image for readers of the target language and intuitively presents how the mask works when people dining in the restaurant.

\section{3) Replacing abstract information}

For readers, unfamiliar information is not the only element that hinders understanding, abstract information will also be the obstacle of absorbing the news. Therefore, abstract information will also be translated applying variation translation.

Example 8

ST: China Inc thinks outside the box as coronavirus keeps consumers at home

TT: 中国商家推出“无接触” 销售降低疫情影响

The source text "thinks outside the box" refers to the contactless delivery that Chinese merchants introduce to sustain marketing during the epidemic. The translator replaces the abstract description of "thinks outside the box" with the specific practices “无接触销售” by Chinese merchants.

\subsection{Translation Strategies Based on Norm-Based Ethics}

Norm-based ethics requires translators to provide translations that conform to the cultural norms of the target language at the time. When translating online news headlines into Chinese, the translated headlines should comply with the standard of the Chinese news headlines on the website. For the bilingual news headlines on the China Daily, the most prominent requirement for cultural norms in the target language is to maintain interaction with readers and arouse readers' interest in reading.

\section{1) Adding interactive semantic content}

For news headlines with declarative sentences in the source text, the translator adds question in target text to interact with readers and express increased intimacy to readers:

Example 9

ST: Italians and French gain more than two kilos on average during coronavirus lockdown

$\mathrm{TT}$ : 居家令期间意大利人和法国人俩月胖了 2 公斤, 你胖了吗?

No question can be found in the source text, but a question “你胖了吗? (Did you get on weight as they do?)" is added by the translation to make the readers empathize.

\section{2) Replacing plain narration}

Adopting metaphors, personifications, or introducing buzzwords of the target language in the target text to make the headlines more interesting, such as Example 10:

Example 10

ST: Coronavirus: How China is keeping busy during quarantine 
TT: 云健身、云泡吧：疫情下的中国人万事皆可 “云”

The “云(Cloud)" in the target text is originating from “Cloud technology". The used “云” in this translation is actually an answer for "How China is keeping busy during quarantine". The target text maintains the structure of the source headline while makes the translation more vivid.

\section{Conclusion}

In this paper, the application of Chesterman's translation ethics in news headline translation (E-C) is illustrated from three aspects, namely the ethics of service, ethics of communication and norm-based ethics. The conclusion is made as follows:

Readers' sense of experience during reading, the service purpose of the bilingual news website itself, readers' cultural expectations and the normative requirements of the news headlines are all the factors to be considered. Translation methods of adding particulars, adding comments, omitting background information and replacing micro information are adopted to cater the service purpose of the news website; methods of shifting perspective, replacing unfamiliar information and replacing abstract information are adopted to strengthen the cultural communication of source and target language; methods of adding interactive semantic content and replacing plain narration are adopted to satisfy the norm requirements of current online news headlines. Thus, translators'subjectivity can be exerted from different dimensions under the guidance of translation ethics. According to translation ethics, different translation strategies and translation methods are independently selected to better coordinate the relationship between translators and translation activities. In this way, the motivation of translation subjectivity is clearly seen, and the fundamentals of the selection of translation strategies and methods are formed.

\section{Conflicts of Interest}

The authors declare no conflicts of interest regarding the publication of this paper.

\section{References}

Chen, Y.-Q. (2020). Importance and Strategy of Compiling News Headlines for New Media. New Media Research, 6, 98-99.

Ge, X.-Q. (2002). The Fetters of a Translator's Subjectivity-From the Source-Text Oriented to the Target-Culture Oriented. Foreign Language Research, 1, 62-65.

Hou, L., \& Xu, L.-Z. (2013). On Translator and Translation Ethics from the Perspective of Andrew Chesterman's Five Models of Translation Ethics. Foreign Language and Literature, 29, 133-136.

Peng, P. (2013). Translation Ethics (p. 95). Beijing: Central Compilation \& and Translation Press.

Wang, X.-L. (2016). Further Discussion on Translation Ethics. Shanghai Journal of Translators, 5, 13-18. 
Xiong, B. (2014). Definition Clarification for Translation Studies-Difference among "Translation Strategies", "Translation Methods" and "Translation Skills" as a Case. Chinese Translators Journal, 35, 82-88. 